\title{
Salicylic Acid-Induced Resistance to Cucumber mosaic virus in Squash and Arabidopsis thaliana: Contrasting Mechanisms of Induction and Antiviral Action
}

\author{
Carl N. Mayers, ${ }^{1}$ Kian-Chung Lee, ${ }^{2}$ Catherine A. Moore, ${ }^{1}$ Sek-Man Wong, ${ }^{2}$ and John P. Carr ${ }^{1}$ \\ ${ }^{1}$ Plant Sciences Department, University of Cambridge, Downing Street, Cambridge CB2 3EA, U.K.; ${ }^{2}$ Department of \\ Biological Sciences, National University of Singapore, Kent Ridge, Singapore 117543, Singapore
}

Submitted 23 August 2004. Accepted 9 December 2004.

\begin{abstract}
Salicylic acid (SA)-induced resistance to Cucumber mosaic virus (CMV) in tobacco (Nicotiana tabacum) results from inhibition of systemic virus movement and is induced via a signal transduction pathway that also can be triggered by antimycin $A$, an inducer of the mitochondrial enzyme alternative oxidase (AOX). In Arabidopsis thaliana, inhibition of CMV systemic movement also is induced by SA and antimycin A. These results indicate that the mechanisms underlying induced resistance to $\mathrm{CMV}$ in tobacco and $A$. thaliana are very similar. In contrast to the situation in tobacco and A. thaliana, in squash (Cucurbita pepo), SA-induced resistance to CMV results from inhibited virus accumulation in directly inoculated tissue, most likely through inhibition of cell-to-cell movement. Furthermore, neither of the AOX inducers antimycin $\mathrm{A}$ or $\mathrm{KCN}$ induced resistance to $\mathrm{CMV}$ in squash. Additionally, AOX inhibitors that compromise SAinduced resistance to $\mathrm{CMV}$ in tobacco did not inhibit SAinduced resistance to the virus in squash. The results show that different host species may use significantly different approaches to resist infection by the same virus. These findings also imply that caution is required when attempting to apply findings on plant-virus interactions from model systems to a wider range of host species.
\end{abstract}

Additional keywords: phloem, plasmodesmata, systemic acquired resistance.

Plants exhibiting systemic acquired resistance (SAR) show a decreased level of susceptibility to many types of pathogen (Dempsey et al. 1999). SAR can occur following a hypersensitive response (HR), a resistance response that often is characterized by rapid localized cell death close to the point of pathogen penetration or entry (Heath 2000). Salicylic acid (SA) is an essential signal for the induction of SAR and the orchestration of the events that occur during the HR, but the relationship among SA, cell death, and resistance is complex and is not yet fully understood (Alvarez 2000; Darby et al. 2000; Gaffney et al. 1993). However, an SAR-like state of enhanced disease

Corresponding author: John P. Carr; Telephone: +44-1223 333900; Fax: +44-1223 333953; E-mail:jpc1005@hermes.cam.ac.uk

Current address of C. N. Mayers: Dstl, Porton Down, Salisbury, SP4 0JQ, U.K.

Current address of C. A. Moore: Lumora Ltd., Institute of Biotechnology, University of Cambridge, Tennis Court Road, Cambridge, CB2 1QT, U.K. resistance can be induced without an HR in plants by treatment with solutions of SA or certain other chemicals (Murphy et al. 1999, 2001; Oostendorp et al. 2001; White et al. 1983).

Cucumber mosaic virus (CMV) has the largest host range of any plant virus and is an important crop pathogen as well as a major model for basic research (Palukaitis and García-Arenal 2003). The CMV genome comprises three positive-sense RNA molecules, RNAs 1 through 3, that can function as mRNAs for the synthesis of the 1a and $2 \mathrm{a}$ replicase proteins and the $3 \mathrm{a}$ movement protein, respectively. During the process of replication, subgenomic mRNAs encoding additional proteins are synthesized. These are RNA 4, which is derived from RNA 3 and encodes the coat protein (CP), and RNA 4A, which is derived from RNA2 and encodes the multifunctional $2 \mathrm{~b}$ protein (Ding et al. 1994).

HR-type resistance against CMV has been demonstrated in several plants, including cowpea (Kim and Palukaitis 1997) and Arabidopsis thaliana (Sekine et al. 2004). However, enhanced resistance to CMV also can be induced without a concomitant HR by treatment of plants with SA or one of its synthetic functional analogues (Smith-Becker et al. 2003), or by pre-infection with unrelated HR-inducing pathogens (Bergstrom et al. 1982; Naylor et al. 1998).

In tobacco treated with solutions of SA, CMV infection is not prevented but the systemic movement of the virus is inhibited and the progress of disease induction is markedly slowed down (Naylor et al. 1998). The nature of this SA-induced resistance to $\mathrm{CMV}$ in tobacco is strikingly different from that induced against certain other viruses in the same host. Whereas the replication and cell-to-cell movement of CMV are unaffected in the directly inoculated leaves of SA-treated plants, both of these processes are inhibited in Tobacco mosaic virus (TMV)- and Potato virus $X$ (PVX)-inoculated leaves (Chivasa et al. 1997; Murphy and Carr 2002; Naylor et al. 1998). The ability of CMV to evade SA-induced resistance to local movement and replication has been attributed convincingly to an effect of the $2 \mathrm{~b}$ protein ( $\mathrm{Ji}$ and Ding 2001). However, it is not known whether the ability of the $2 \mathrm{~b}$ protein to subvert SA-induced resistance is related to its activity as a suppressor of RNA silencing.

SA-induced resistance to viruses in tobacco and $A$. thaliana is mediated in part by a pathway that appears to involve signals transduced through changes in redox or reactive oxygen species (ROS) in the mitochondria (Singh et al. 2004). This idea is supported by several lines of evidence. These include the observations that resistance to TMV in tobacco, and to the Tobamovirus Turnip vein clearing virus in A. thaliana, can be induced 
with nontoxic levels of antimycin A or cyanide (Chivasa and Carr 1998; Wong et al. 2002). These chemicals, and SA itself, impede electron flow through the respiratory electron transport chain and enhance ROS levels in the mitochondria (Maxwell et al. 1999; Norman et al. 2004; Xie and Chen 1999). Other support comes from a study which showed that the characteristics of SA- and antimycin A-induced resistance to TMV are altered in transgenic tobacco plants with altered levels of alternative oxidase (AOX), an enzyme that negatively regulates mitochondrial ROS levels (Gilliland et al. 2003).

However, the same study showed that signaling in the mitochondria cannot be the sole means by which SA induces resistance to tobamoviruses, and it was concluded that an additional antiviral mechanism is induced via a nonmitochondrial signaling pathway (Gilliland et al. 2003; Singh et al. 2004). It was proposed that this additional mechanism is based on RNA silencing, a widely conserved sequence-specific RNA degradation mechanism that can function in virus resistance (Moissiard and Voinnet 2004). In this instance, it is thought that induction of RNA silencing is mediated by the host RNA-dependent RNA polymerase, RdRP1, an enzyme which is known to enhance turnover of TMV RNA (Xie et al. 2001) but not CMV RNA (Yang et al. 2004).

Work in tobacco with salicylhydroxamic acid (SHAM), an inhibitor of AOX, indicates that SA-induced resistance to the systemic movement of CMV is mediated through the mitochondrial signaling pathway (Naylor et al. 1998). Consistent with this, it was found that the CMV $2 \mathrm{~b}$ protein, which partially protects CMV from SA-induced resistance, affects the steady state accumulation of Aox mRNA (Ji and Ding 2001). However, it is not known if the characteristics of SA-induced resistance to CMV seen in tobacco (i.e., inhibition of systemic movement induced via the mitochondrial signaling pathway) are the same in other plants.

In this study, we examined chemically induced resistance to CMV in A. thaliana, currently the most intensively studied model host plant, and Cucurbita pepo (squash), a crop plant and frequently used experimental host for studies of CMV. We found that, in A. thaliana as in tobacco, SA and antimycin A treatments inhibited the systemic movement of CMV. However, in squash, only SA induced resistance to $\mathrm{CMV}$ and this was most likely due to inhibition of viral cell-to-cell movement. The results indicate that the mechanisms of SA-induced resistance may differ markedly between host species.

\section{RESULTS}

Treatment of A. thaliana with either SA or antimycin A delays the onset of CMV systemic movement.

A. thaliana plants were sprayed with water or solutions of 1 $\mathrm{mM}$ SA or $50 \mu \mathrm{M}$ antimycin A daily for 5 days prior to inoculation with CMV. We found that, although both chemical treatments induced a delay in the appearance of CMV in the noninoculated leaves, there was no apparent SA- or antimycin A-induced delay in the accumulation of virus in the directly inoculated leaves (Fig. 1). The results show that neither SA nor antimycin $\mathrm{A}$ induced any apparent effect on CMV replication or cell-to-cell movement in the inoculated leaves (Fig. 1A). However, it does appear that both chemicals induce resistance to the systemic movement of CMV (Fig. 1B and C). In both treated and untreated plants, the appearance of virus-induced disease symptoms (deformation and yellowing of younger leaves) lagged behind the first appearance of detectable viral $\mathrm{CP}$ in the upper leaves. Symptoms became apparent in untreated plants at approximately 12 days postinoculation but were delayed in SA- and antimycin A-treated plants by approximately 5 days (data not shown). This suggests that, in A. thaliana, induced resistance to CMV operates via a similar or identical mechanism to SA-induced resistance to the same virus in tobacco (Naylor et al. 1998).

\section{SA treatment delays the onset of CMV-induced disease symptoms in squash.}

To determine whether SA can induce resistance to CMV in squash, newly emerged seedlings were watered with $2 \mathrm{mM} \mathrm{SA}$ or water for 5 days prior to inoculation with $\mathrm{CMV}$ at 50 or 5 $\mu \mathrm{g} / \mathrm{ml}$. Upper, noninoculated leaves were monitored over the subsequent 10 days for the development of systemic symptoms: leaf distortion, petiole curling (epinasty), and mosaic. SA treatment was able to delay or, in a proportion of the
A

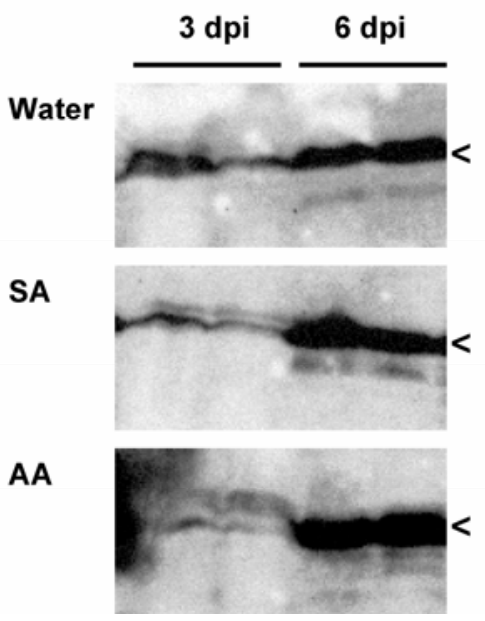

B

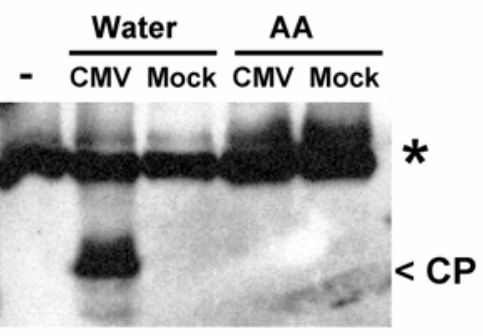

C

Water SA

Dpi: $\quad \begin{array}{lllllllllll}4 & 6 & 8 & 10 & 12 & \times & 4 & 6 & 8 & 10 & 12\end{array}$

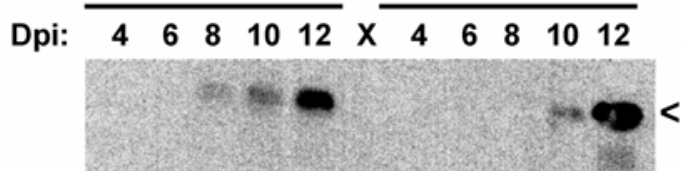

Fig. 1. Systemic movement of Cucumber mosaic virus (CMV) is inhibited in Arabidopsis thaliana plants sprayed with salicylic acid (SA) or antimycin A (AA) solutions. Plants ( 3 weeks postgermination) were sprayed with solutions of $1 \mathrm{mM} \mathrm{SA}, 50 \mu \mathrm{M}$ AA. or water for 5 days before being mock inoculated or inoculated with CMV on two or three leaves. At various times after inoculation (days postinoculation [dpi]), A, directly inoculated leaves or $\mathbf{B}$ and $\mathbf{C}$, noninoculated leaves were harvested and proteins extracted for Western immunoblot analysis with anti-CMV coat protein (CP) serum. Protein samples run on blot B were harvested at $12 \mathrm{dpi}$ (at which time symptoms were apparent on the noninoculated leaves of water-sprayed, CMV-inoculated plants but not on the AA-treated, CMV-inoculated plants; data not shown) and this blot was simultaneously probed with anti-RUBISCO large subunit (LSU) serum to demonstrate equal protein loading. Primary antibody binding was detected using goat anti-rabbit immunoglobulin $\mathrm{G}$ conjugated to horseradish peroxidase (HRP) and a chemiluminescent HRP substrate (NEN 'Renaissance'). The positions of CMV CP or LSU are indicated by < and *, respectively. Lane X in panel 1C indicates an unloaded gel lane. 
plants, prevent the onset of symptoms in plants inoculated with the lower inoculum concentration. Even in plants inoculated with the higher virus concentration, pretreatment with SA still was able to slow the progress of symptom development, although all of these plants eventually succumbed to the disease (Fig. 2). Thus, in squash, SA can delay the onset of CMVinduced disease even in plants inoculated with relatively high concentrations of purified virus. This is similar to the situation seen previously in tobacco (Naylor et al. 1998).

\section{In squash, $\mathrm{SA}$ inhibits the accumulation of $\mathrm{CMV}$ in the directly inoculated tissue.}

We investigated whether the SA-induced delay in the onset of CMV-induced disease (Fig. 2) could be attributed to resistance to the replication or cell-to-cell movement of CMV in the directly inoculated tissue, or to inhibition of virus systemic movement. Viral RNA accumulation was examined in squash leaf disks that had been pretreated with water, $0.5 \mathrm{mM} \mathrm{SA}$, or

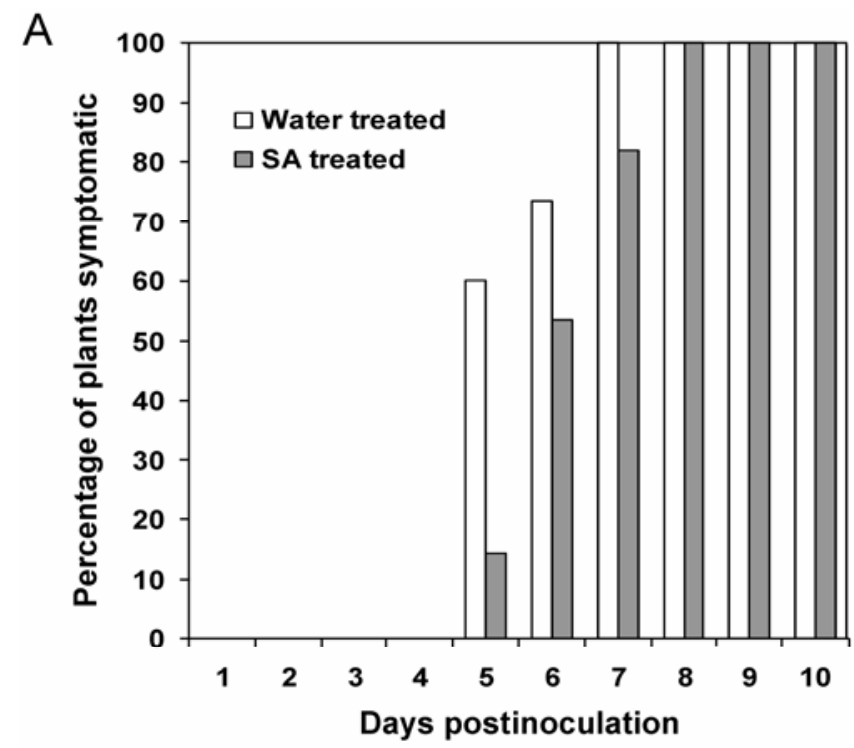

B

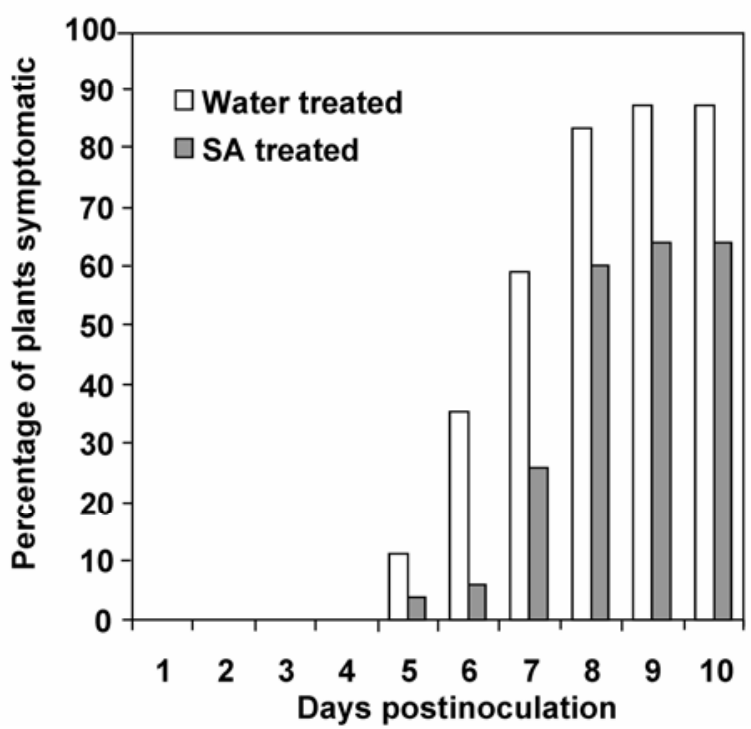

Fig. 2. Salicylic acid (SA) treatment delays the onset of Cucumber mosaic virus (CMV)-induced disease symptoms in squash (Cucurbita pepo). Symptom development was monitored in squash plants inoculated with $\mathbf{A}$, Fny-CMV at $50 \mu \mathrm{g} \mathrm{ml}^{-1}$ after spraying with water $(n=58)$ or $2 \mathrm{mM} \mathrm{SA}(n=$ 72) or B, Fny-CMV at $5 \mu \mathrm{g} \mathrm{ml}^{-1}$ after spraying with water $(n=54)$ or 2 mM SA $(n=50)$. Plants were classed as symptomatic when distortion or chlorosis was apparent on noninoculated leaves.
$0.5 \mathrm{mM}$ 3-hydroxybenzoic acid (HBA, an isomer of SA) for 3 days prior to inoculation with the virus (Fig. 3A). At 2 days postinoculation, the accumulation of viral RNAs was undetectable in SA-treated, CMV-inoculated leaf tissue; whereas, in control tissue, it was already abundant (Fig. 3A). This inhibition of viral RNA accumulation was a surprising result because, in tobacco (Naylor et al. 1998) and A. thaliana (Fig. 1), SA does not induce resistance to CMV RNA or protein accumulation in the directly inoculated tissue. Treatment with HBA had no detectable affect on the accumulation of CMV, showing that the decrease in viral accumulation was specific to SA and not due to some general toxic effect of treating squash tissue with phenolic compounds (Fig. 3A). We found that inhibition of CMV RNA accumulation in directly inoculated squash leaf tissue was dependent upon the concentration of both SA and the inoculum (Fig. 3B). Thus, resistance to viral RNA accumulation was less effective when the inoculum concentration was increased or the concentration of SA decreased (Fig. 3B). These results indicate that, in SA-treated squash, the delay in the onset of CMV-induced symptom expression (Fig. 2) is related to the ability of the chemical to inhibit viral replication or cell-to-cell movement in the inoculated tissue (Fig. 3).

\section{Cyanide, antimycin A, and SHAM do not affect induction of resistance to CMV in directly inoculated squash tissue.}

In tobacco and $A$. thaliana, respiratory inhibitors such as cyanide and antimycin A can induce resistance to CMV as well as other viruses and, in tobacco, the AOX inhibitor SHAM antagonizes SA-induced resistance to TMV and CMV (Fig. 1) (Chivasa and Carr 1998; Gilliland et al. 2003; Naylor et al. 1998; Wong et al. 2002). Therefore, we examined whether the SAinduced inhibition of CMV accumulation is affected by addition of SHAM and another AOX inhibitor, n-propylgallate (NPG), or if cyanide and antimycin A could induce resistance to CMV in squash. Neither SHAM nor NPG was able to prevent the SAinduced resistance to CMV RNA accumulation in directly inoculated squash leaf disks (Fig. 4). This result by itself was not wholly unexpected because SHAM is not taken up well by all plant tissues and, for example, is not an effective antagonist of SA in A. thaliana (Wong et al. 2002). However, neither cyanide (Fig. 4) nor antimycin A (data not shown) treatment induced resistance to $\mathrm{CMV}$ in squash tissue. These results confirm that, in squash, the induction mechanism for resistance to CMV differs markedly from that in tobacco and A. thaliana.

\section{The effects of SA on CMV accumulation in squash protoplasts.}

The reduction in CMV accumulation in leaf disks treated with SA could be due to inhibition of either viral cell-to-cell movement or viral replication. To distinguish between these possibilities, protoplasts were prepared from squash leaf tissue from plants watered normally or sprayed with $1 \mathrm{mM} \mathrm{SA}$. Protoplasts were inoculated with CMV by electroporation with viral RNA and incubated in the presence or absence of SA (Fig. 5). Following incubation, proteins were extracted and analyzed by Western immunoblotting for the presence of CMV CP. It was found that incubation with SA did not cause any obvious decrease in the accumulation of CMV CP, indicating that replication of the virus was unaffected by the presence of the chemical (Fig. 5). In all the squash protoplast experiments, it was noted that SA consistently induced a protein, faintly visible on the Western immunoblots, which was slightly larger than the CMV CP (Fig. 5). However, measurement of protein synthesis by measurement of incorporation of $\mathrm{L}-\left[{ }^{35} \mathrm{~S}\right]$ methionine showed that, in protoplasts from SA-treated plants, total protein synthesis was decreased by approximately $35 \%$ compared with the level observed in protoplasts from un- 
treated plants (data not shown). This indicates that the high level of CMV CP accumulation in SA-treated protoplasts was not due to a generalized increase in protein biosynthesis in these cells. In other experiments, protoplasts were prepared from untreated plants, inoculated with CMV by electroporation with viral RNA, and incubated in the presence or absence of SA. In these experiments, it also was found that CMV CP accumulation reached similar levels (data not shown). Because there was no resistance exhibited at the single cell level, we conclude that the resistance to CMV seen in intact SA-treated squash tissue is most likely to result from inhibition of viral cell-to-cell movement.

\section{DISCUSSION}

We have found that treatment of squash plants with SA delays the onset of CMV infection and that this is due at least in part to the inhibition of the cell-to-cell movement of the virus. Resistance to CMV was not induced by treatment with cyanide or antimycin A, nor was SA-induced resistance inhibited by SHAM which, at least in tobacco, inhibits the induction of resistance by SA (Chivasa et al. 1997; Naylor et al. 1998; Wong et al. 2002). In contrast, resistance to CMV in A. thaliana was induced by both SA and antimycin A and appeared to be due to inhibition of systemic virus movement. This indicates that the mechanisms of action and induction underlying SA-induced resistance to CMV in A. thaliana are similar to those found in tobacco (Naylor et al. 1998), although this is the first direct demonstration that a respiratory inhibitor can induce resistance to CMV. Another difference worth noting between the two plants used in this study is that a higher concentration of CMV is needed to reliably infect $A$. thaliana than is needed to infect squash. Thus, to obtain high-efficiency infection of $A$. thaliana, the inoculum concentration used was $50 \mu \mathrm{g} / \mathrm{ml}$, whereas $5 \mu \mathrm{g} / \mathrm{ml}$ was used for most experiments with squash. The reason for this is unclear but simply may be related to the far smaller surface area available for inoculation on the leaves of A. thaliana versus squash. Overall, the results show that the resistance mechanisms induced by SA and the signal pathways by which they are triggered can differ considerably between plant species.

Higher plants possess a unique transport and communication network based upon the interconnected nature of almost all of the cells in the plant body. This complex symplastic network is formed at the local level by plasmodesmata, bridges of cytoplasm that penetrate through the cell walls separating neighboring cells. They may be formed during the process of cell division (primary plasmodesmata) or produced at later stages of development (secondary plasmodesmata) (Blackman and Overall 2001). Symplastic communication and transport can occur over longer distances between tissues and organs through the phloem tissues, the main conduit for transport of soluble carbohydrate, which are connected via plasmodesmata to the surrounding tissues (Blackman and Overall 2001; Nelson and van Bel 1997; van Bel 2003). In order to reach all parts of a plant, viruses must be able to exploit this complex network of plasmodesmata and phloem elements.

A

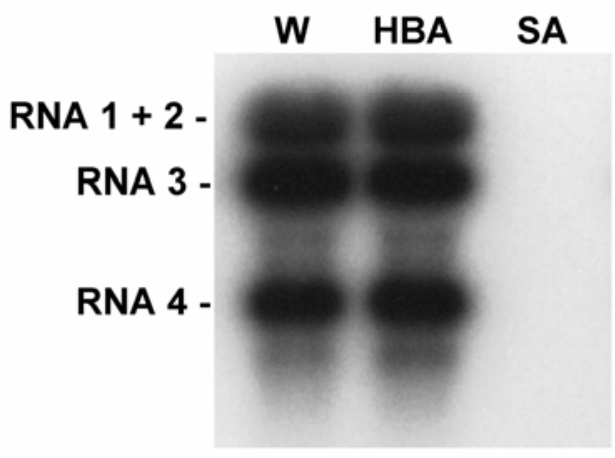

B

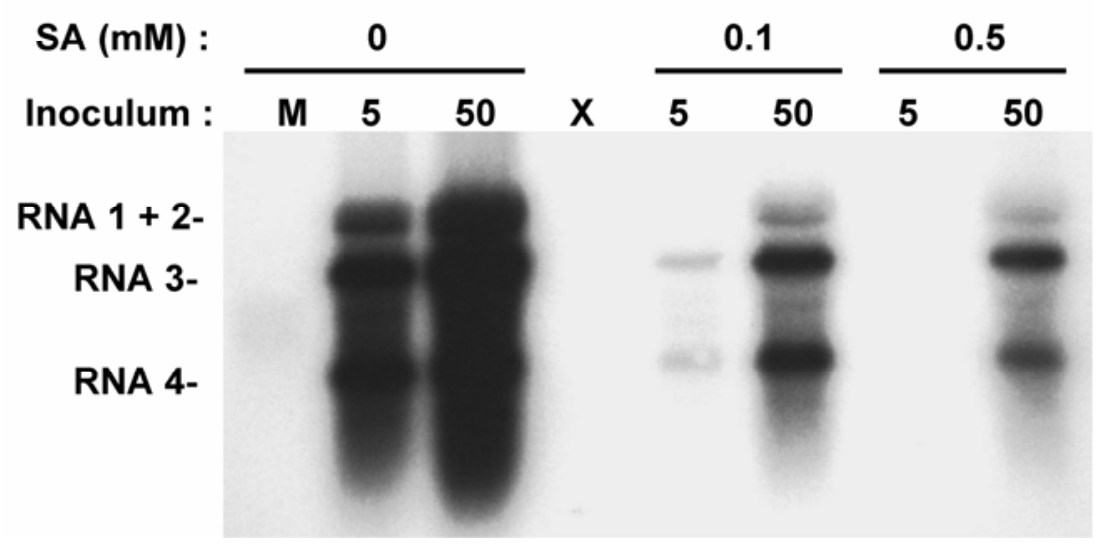

Fig. 3. Viral RNA accumulation is inhibited in salicylic acid (SA)-treated, Cucumber mosaic virus (CMV)-inoculated squash leaf tissue. A, Squash leaf disks were floated on water (W), $0.5 \mathrm{mM} \mathrm{SA}$, or $0.5 \mathrm{mM}$ 3-hydroxybenzoic acid (HBA; an isomer of SA) for 3 days before inoculation with Fny-CMV at $5 \mu \mathrm{mg} \mathrm{l}^{-1}$. Total RNA was extracted 2 days postinoculation. Equal amounts (10 $\mu \mathrm{g})$ of RNA per sample were electrophoresed on a 1\% (wt/vol) agarose gel and blotted to nitrocellulose, which was probed with a ${ }^{32} \mathrm{P}$-labeled CMV-specific transcript. Hybridizing bands were visualized by autoradiography. B, Steady-state levels of CMVspecific RNAs in directly inoculated squash leaf tissue. Squash leaf disks were floated for 3 days on water containing 0 , 0.1 , or 0.5 mM SA prior to mock inoculation (M), or inoculation with Fny-CMV at 5 or $50 \mu \mathrm{g} \mathrm{ml}^{-1}$. RNA blot analysis was carried out at 2 days postinoculation as for A; X indicates an empty gel lane. 
The inhibition of systemic movement is the predominant expression of SA-induced resistance to CMV in tobacco and A. thaliana; however, in squash, cell-to-cell movement is impaired. Could this be explained by differences in the fine structure of these plants' vascular tissues? Broadly speaking, virus systemic movement follows the translocation of photosynthates, predominantly sucrose, from carbon source to carbon sink tissues (Nelson and van Bel 1997). However, the sucrose and virus may briefly part company during loading from the mesophyll cells into the phloem. This is because, for viruses like CMV, the entire route from the leaf mesophyll cells to the sieve element-companion cell complex must occur via plasmodesmata (i.e., symplastically). However, the route taken by sucrose can be symplastic or apoplastic, depending upon the plant species (ap Rees 1994; Truernit 2001). Whether the transfer of sucrose occurs predominantly via the symplastic or apoplastic route depends upon the abundance of plasmodesmata linking the phloem tissue (sieve elements and companion cells) and the surrounding mesophyll cells (Truernit 2001). Detailed electron microscopic examination has shown that, in squash, which is a symplastic loader, these connections are abundant (Gamalei 1989). In contrast, the number of plasmodesmal connections per square micrometer of this interface is approximately 600fold less in tobacco and, in A. thaliana, there are between 37and 10-fold fewer connections, depending upon the correction factor used (Gamalei 1991; Haritatos et al. 2000).
We suggest that, in tobacco and A. thaliana, where there are relatively few plasmodesmal connections between the mesophyll and phloem tissue, any inhibition of virus movement through the plasmodesmata at this interface will significantly compromise the ability of a virus to spread out of the primary inoculated leaf. In squash, by contrast, the large number of plasmodesmal connections between the mesophyll and phloem cells may render any inhibition of virus movement at this interface to be less effective in preventing systemic virus movement from occurring. This may have placed a selective pressure on squash, and probably other cucurbits, for SA-induced resistance to CMV to target an earlier stage in virus invasion than we see in tobacco or A. thaliana.

We have proposed that, in A. thaliana and tobacco, induced resistance to viruses is controlled in part by ROS- or redoxmediated signaling within the mitochondria (Singh et al. 2004). Evidence for this idea includes the observation that subtoxic solutions of cyanide and antimycin A, which are known to enhance mitochondrial ROS levels, are able to induce resistance to several viruses, including CMV (Fig. 1) (Chivasa and Carr 1998; Gilliland et al. 2003; Wong et al. 2002). In tobacco, SHAM (an inhibitor of AOX, a negative regulator of ROS production) antagonized the induction by SA of resistance against TMV, PVX, and CMV (Chivasa et al. 1997; Naylor et al. 1998). In contrast, cyanide and antimycin A did not induce resistance to CMV in squash (Fig. 4). Furthermore, we found that $\mathrm{SA}$-induced resistance to $\mathrm{CMV}$ in squash showed no sen-

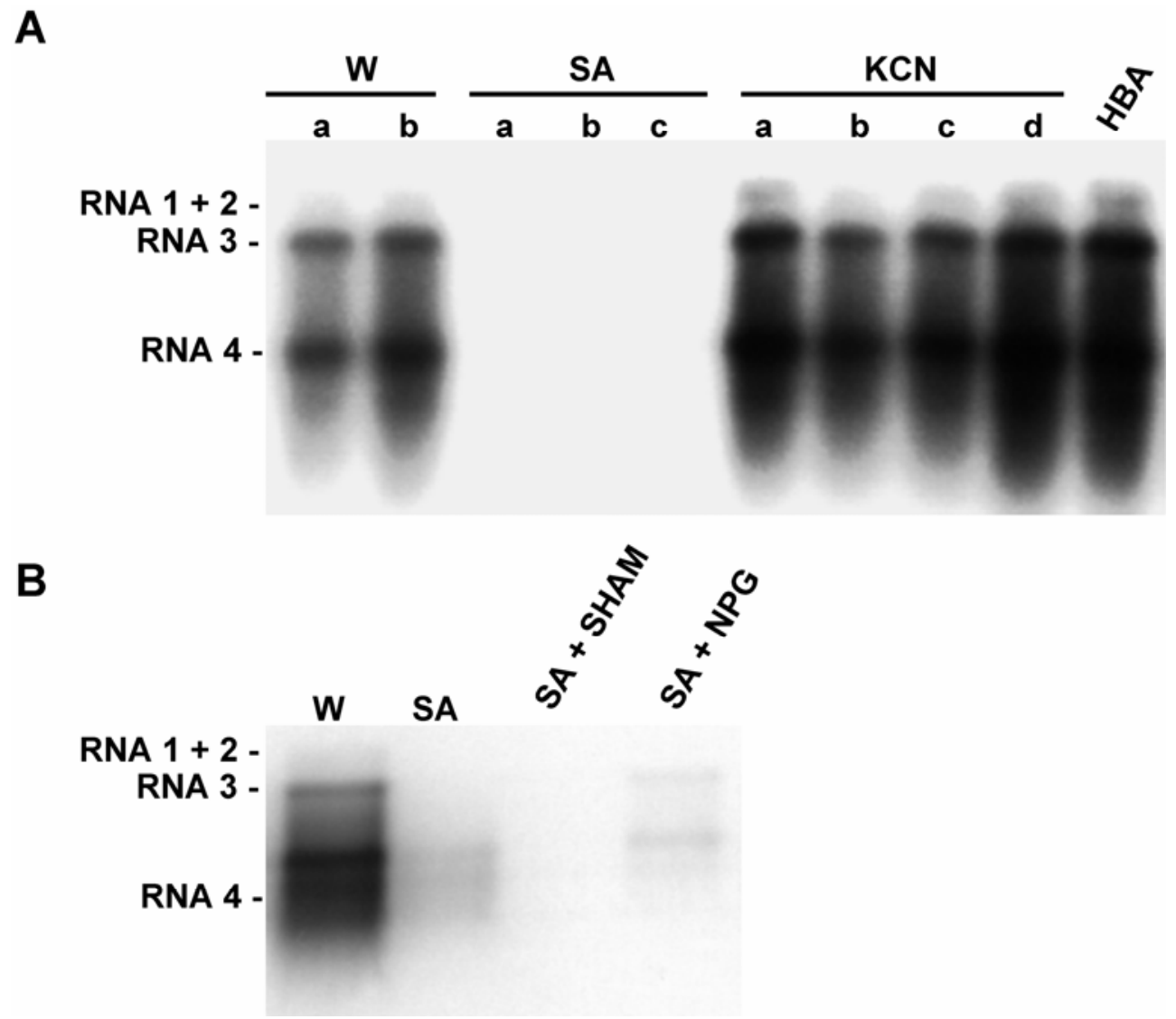

Fig. 4. Cucumber mosaic virus (CMV) RNA accumulation in squash leaf tissue is not affected by cyanide or alternative oxidase inhibitors. A, Groups of 10 10-mm-diameter squash leaf disks were pretreated with water (W: two sets of disks, a and b), 0.5 mM salicylic acid (SA) (three sets of disks, a, b, and c), 50 $\mathrm{mM} \mathrm{KCN}$ (fours sets of disks, a-d), or $0.5 \mathrm{mM} 3$-hydroxybenzoic acid (HBA; one set of disks) for 3 days before inoculation with Fny-CMV at $5 \mu \mathrm{g}$ ml ${ }^{-1}$. Total RNA was extracted 2 days postinoculation, equal amounts of RNA were analyzed by agarose gel electrophoresis, and CMV-specific RNAs were detected by probing with a ${ }^{32} \mathrm{P}$-labeled CMV-specific transcript and hybridizing bands were visualized by autoradiography. B, Accumulation of CMVspecific RNAs in squash leaf disks inoculated with Fny-CMV at $5 \mu \mathrm{g} \mathrm{m}{ }^{-1}$ following flotation on water (W), $0.5 \mathrm{mM} \mathrm{SA}$, or $0.5 \mathrm{mM} \mathrm{SA} \mathrm{plus} 1 \mathrm{mM}$ salicylhydroxamic acid (SHAM) or $1 \mathrm{mM}$-propylgallate (NPG). In some of these RNA samples, there has been some degradation leading to a decreased level of RNAs 1 and 2, relative to the levels of RNAs 3 and 4. 
sitivity to the AOX inhibitors SHAM and NPG. The results show that defensive signaling pathways in cucurbits differ significantly from those found in tobacco and $A$. thaliana because, in squash, the mitochondrial signaling mechanism appears to be absent, or at least not used for induction of resistance to CMV cell-to-cell movement. Another difference between defensive signaling in squash compared with tobacco appears to be that the pathway required for SA-induced resistance to CMV is unlikely to be affected by the CMV $2 \mathrm{~b}$ protein. In tobacco, this viral counter defense factor somehow allows CMV to evade SA-induced resistance in the directly inoculated tissue (Ji and Ding 2001) but apparently this is not occurring in squash, in which SA does inhibit the accumulation of the virus in the inoculated tissue.

In a recently published study, Thaler and associates (2004) presented evidence challenging a widespread view (based predominantly upon studies in A. thaliana) that induced resistance to fungal and bacterial pathogens is regulated by salicylate or jasmonate, respectively, depending upon whether the pathogen is a biotroph or necrotroph. In our study, we have shown that important features of an induced resistance mechanism may not be conserved between plants even when exactly the same pathogen, in this case a virus, is involved. Specifically, we found that the characteristics of SA-induced resistance to CMV are very similar in tobacco and A. thaliana but very different in squash. Thus, a virus that is resisted in one way by plants of one species may be resisted in another host species using a different mechanism induced by a distinctly different signaling pathway. This is in line with a suggestion made in an earlier publication in an attempt to explain why mechanisms of SA-induced resistance to Alfalfa mosaic virus may differ between host species (Hooft van Huijsduijnen et al. 1986; Murphy et al. 1999). However, even with the specific example of CMV, recent studies show that one cannot assume that SA-mediated pathways are the only means of responding against this virus (Ryu et al. 2004; Sekine et al. 2004). These studies, our own, and those of Thaler and associates (2004) suggest that it is still too early to attempt to construct general rules governing signaling in plant-pathogen interactions based on work in a restricted number of model plants.

\section{MATERIALS AND METHODS}

Virus and plant materials.

Virions of CMV strain Fny (Roossinck and Palukaitis 1990) were purified by the method described by Lot and associates (1972). To promote synchronous germination and development of A. thaliana L. Heyhn. (ecotype Col-0), seed first was vernalized at $4^{\circ} \mathrm{C}$ in the dark for 5 days prior to transfer to a growth room for germination. Subsequently, the plants were grown under short day conditions ( $9 \mathrm{~h}$ of light) at $24^{\circ} \mathrm{C}$ to maximize vegetative growth and plants were used for experiments at 3 to 4 weeks after germination. Inoculation of $A$. thaliana plants was performed using a fine sable paintbrush to apply a suspension of CMV in water at $50 \mu \mathrm{g} / \mathrm{ml}$ onto leaves sprinkled with Carborundum.

Seed of zucchini squash (C. pepo L. cv. Black Beauty) were a gift from P. Palukaitis (Scottish Crop Research Institute, Dundee, U.K.). Seed were germinated in compost (Levington M3; Berrycroft Stores, Wellingham, U.K.) in a glasshouse maintained at 23 to $27^{\circ} \mathrm{C}$ with a combination of natural light and fluorescent light. Squash leaves or leaf disks were inoculated with CMV suspensions using cotton tips on adaxial surfaces previously dusted with Carborundum powder.

Squash protoplasts were prepared from untreated or chemically treated plants and inoculated with CMV by electropora- tion with viral RNA using the procedures of Lee and associates (2001).

\section{Chemical treatments.}

All chemicals for plant treatment were obtained from SigmaAldrich, except NPG (Lancaster Synthesis, Morecambe, Lancashire, U.K.). Chemical solutions for plant treatments were prepared as previously described (Chivasa and Carr 1998; Gilliland et al. 2003; Wong et al. 2002). A. thaliana plants were sprayed with water or solutions of $1 \mathrm{mM} \mathrm{SA}$ or $50 \mu \mathrm{M}$ antimycin A daily for 4 days (Wong et al. 2002) prior to inoculation with CMV. At 4 days prior to inoculation with CMV, squash plants were sprayed with 2-mM SA solutions and on subsequent days watered with the SA solution. For 3 days prior to inoculation, squash leaf disks $(10 \mathrm{~mm}$ in diameter) were floated (adaxial surface downward) on $2 \mathrm{ml}$ of test solution (10 disks per treatment) in a 25-well plastic plate (Bibby Sterilin, Stone, Staffordshire, U.K.) at a constant temperature of $25^{\circ} \mathrm{C}$ with a $14: 10-\mathrm{h}$ light/dark ratio (illumination of $65 \mu$ mole photons $\mathrm{m}^{-2} \mathrm{~s}^{-1}$ ). For antimycin A treatment, leaf tissue was infiltrated with the solution prior to disk excision and flotation (Chivasa and Carr 1998). After inoculation, leaf disks were replaced on their respective solutions and incubated for a further 2 days. Experiments were carried out at least three times.

\section{Extraction and analysis}

of viral RNA and protein in plant material.

RNA extraction was carried out using the method of Chomczynski and Sacchi (1987). RNA was subjected to denaturing agarose gel electrophoresis and CMV-specific RNAs were detected by Northern blot hybridization using a ${ }^{32} \mathrm{P}$-labeled riboprobe complementary to the conserved 3' terminal region of the Fny-CMV RNAs (Carr et al. 1994; GalOn et al. 1994). CMV CP was detected by Western immunoblot analysis using a polyclonal anti-CP serum (gift of P. Palukaitis) as described previously using colorimetric(squash protoplast experiments) or chemiluminescence- $(A$. thaliana experiments) based detection of antibody binding (Naylor et al. 1998; Wang et al. 2004). Some Western immunoblots were probed simultaneously with anti-RUBISCO large subunit serum to demonstrate equal protein loading (Gilliland et al. 2003).

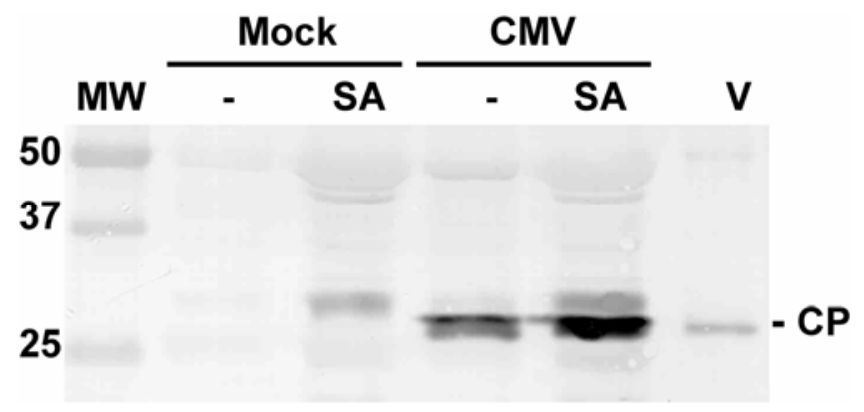

Fig. 5. Cucumber mosaic virus (CMV) accumulation in squash protoplasts from plants treated with salicylic acid (SA). Squash leaf protoplasts were prepared from plants that had been watered normally (-) or treated by spraying with $2 \mathrm{mM}$ SA 5 days prior to preparation and subsequent daily watering with the SA solution. Protoplasts were subjected to electroporation in the absence (Mock inoculation) or presence of CMV RNA and incubated for $24 \mathrm{~h}$. Protein from the protoplasts was analyzed for the presence of CMV coat protein (CP) by Western immunoblot analysis. Primary antibody binding was detected using a goat anti-rabbit immunoglobulin $\mathrm{G}$ conjugated to alkaline phosphatase and a colorogenic substrate. Each gel lane was loaded with protein from approximately 20,000 protoplasts. Positions of prestained protein size markers (MW) and the CMV CP are indicated. Lane V was loaded with authentic CMV to act as a marker. 


\section{ACKNOWLEDGMENTS}

Work in J. P. Carr's laboratory was funded by a grant from The Leverhulme Trust, C. N. Mayers was a recipient of a studentship from the U.K. Biotechnological and Biological Sciences Research Council, and National University of Singapore provided partial financial support to S.-M. Wong through research grant RP 154-000-186-112. We thank P. Palukaitis and A. Murphy for many useful discussions, E. Truernit and J. Hibberd for helpful advice on phloem anatomy, and C. York for skilful technical assistance.

\section{LITERATURE CITED}

Alvarez, M. E. 2000. Salicylic acid in the machinery of hypersensitive cell death and disease resistance. Plant Mol. Biol. 44:429-442.

ap Rees, T. 1994. Plant physiology. Virtue on both sides. Curr. Biol. 4:557559.

Bergstrom, G. C., Johnson, M. C., and Kuć, J. 1982. Effects of local infection of cucumber by Colletotrichum lagenarium, Pseudomonas lachrymans, or tobacco necrosis virus on systemic resistance to Cucumber mosaic virus. Phytopathology 72:922-926.

Blackman, L. M,. and Overall, R. L. 2001. Structure and function of plasmodesmata. Aust. J. Plant Physiol. 28:709-727.

Carr, J. P., Gal-On, A., Palukaitis, P., and Zaitlin, M. 1994. Replicase-mediated resistance to cucumber mosaic virus in transgenic plants involves suppression of both virus replication in the inoculated leaves and long distance movement. Virology 199:439-447.

Chivasa, S., and Carr, J. P. 1998. Cyanide restores $N$ gene mediated resistance to tobacco mosaic virus in transgenic tobacco expressing salicylic acid hydroxylase. Plant Cell 10:1489-1498.

Chivasa, S., Murphy, A. M., Naylor, M., and Carr, J. P. 1997. Salicylic acid interferes with tobacco mosaic virus replication via a novel salicylhydroxamic acid-sensitive mechanism. Plant Cell 9:547-557.

Chomczynski, P., and Sacchi, N. 1987. Single-step method of RNA isolation by acid guanidinium thiocyanate-phenol-chloroform extraction. Anal. Biochem. 162:156-159.

Darby, R. M., Maddison, A., Mur, L. A. J., Bi, Y.-M., and Draper, J. 2000. Cell-specific expression of salicylate hydroxylase in an attempt to separate localized HR and systemic signaling establishing SAR in tobacco. Mol. Plant Pathol. 1:115-123.

Dempsey, D. A., Shah, J., and Klessig, D. F. 1999. Salicylic acid and disease resistance in plants Crit. Rev. Plant Sci. 18:547-575.

Ding, S.-W., Anderson, B. J., Haase, H. R., and Symons, R. H. 1994. New overlapping gene encoded by the cucumber mosaic virus genome. Virology 198:593-601.

Gaffney, T., Friedrich, L., Vernooij, B., Negrotto, D., Nye, G., Uknes, S., Ward, E., Kessmann, H., and Ryals, J. 1993. Requirement of salicylic acid for the induction of systemic acquired resistance. Science 261:754-756.

Gal-On, A., Kaplan, I., Roossinck, M. J., and Palukaitis, P. 1994. The kinetics of infection of zucchini squash by cucumber mosaic virus indicate a function for RNA 1 in virus movement. Virology 205:280-289.

Gamalei, Y. V. 1989. Structure and function of leaf minor veins in trees and herbs. A taxonomic review. Trees 3:96-110.

Gamalei, Y. V. 1991. Phloem loading and its development related to plant evolution from trees to herbs. Trees 5:50-64.

Gilliland, A., Singh, D. P., Hayward, J. M., Moore, C. A., Murphy, A. M., York, C. J., Slator, J., and Carr, J. P. 2003. Genetic modification of alternative respiration has differential effects on antimycin A-induced versus salicylic acid-induced resistance to Tobacco mosaic virus. Plant Physiol. 132:1518-1528.

Haritatos E., Medville, R., and Turgeon, R. 2000. Minor vein structure and sugar transport in Arabidopsis thaliana. Planta 211:105-111.

Heath, M. C. 2000. Hypersensitive response-related death. Plant Mol. Biol. 44:321-334.

Hooft van Huijsduijnen, R. A. M., Alblas, S. W., De Rijk, R. H., and Bol, J. F. 1986. Induction by salicylic acid of pathogenesis related proteins and resistance to alfalfa mosaic virus in various plant species. J. Gen. Virol. 67:2137-2143.

Ji, L.-H., and, Ding, S.-W. 2001. The suppressor of transgene RNA silencing encoded by Cucumber mosaic virus interferes with salicylic acid-mediated virus resistance. Mol. Plant-Microbe Interact. 14:715-724.

Kim, C. H., and Palukaitis, P. 1997. The plant defense response to Cucumber mosaic virus in cowpea is elicited by the viral polymerase gene and affects virus accumulation in single cells. EMBO (Eur. Mol. Biol. Organ.) J. 16:4060-4068.

Lee, K.-C., Koh, A., Loh, C. S., and Wong, S.-M. 2001. Cucurbit protoplast isolation for the study of plant virus replication. J. Virol. Methods
91:21-27.

Lot, H., Marrou, J., Quiot, J. B., and Esvan, C. 1972. Contribution a l'etude de virus de la mosaique du concombre (CMV). II. Methode de purification rapide du virus. Ann. Phytopathol. 4:25-38.

Maxwell, D. P., Wang, Y., and McIntosh, L. 1999. The alternative oxidase lowers mitochondrial reactive oxygen production in plant cells. Proc. Natl. Acad. Sci. U.S.A. 96:8271-8276.

Moissiard, G., and Voinnet, O. 2004. Viral suppression of RNA silencing in plants. Mol. Plant Pathol. 5:71-82.

Murphy, A. M., and Carr, J. P. 2002. Salicylic acid has cell-specific effects on Tobacco mosaic virus replication and cell-to-cell movement. Plant Physiol. 128:552-563.

Murphy, A. M., Chivasa, S., Singh, D. P., and Carr, J. P. 1999. Salicylic acid induced resistance to viruses and other pathogens: a parting of the ways? Trends Plant Sci. 4:155-160.

Murphy, A. M., Gilliland, A., Wong, C. E., West, J., Singh, D. P., and Carr, J. P. 2001. Induced resistance to viruses. Eur. J. Plant Pathol. 107:121128.

Naylor, M., Murphy, A. M., Berry, J. O., and Carr, J. P. 1998. Salicylic acid can induce resistance to plant virus movement. Mol. Plant-Microbe Interact. 11:860-868.

Nelson, R. S., and van Bel, A. J. E. 1997. The mystery of virus trafficking into, through and out of the vascular tissue. Prog. Bot. 59:476-533.

Norman, C., Howell, K. A., Millar, A. H., Whelan, J. M., and Day, D. A. 2004. Salicylic acid is an uncoupler and inhibitor of mitochondrial electron transport. Plant Physiol. 134:492-501.

Oostendorp, M., Kunz, W., Dietrich, B., and Staub, T. 2001. Induced resistance in plants by chemicals. Eur. J. Plant Pathol. 107:19-28.

Palukaitis P., and García-Arenal, F. 2003. Cucumoviruses. Adv. Virus Res. 62:241-323.

Roossinck, M. J., and Palukaitis, P. 1990. Rapid induction and severity of symptoms in zucchini squash (Cucurbita pepo) map to RNA 1 of $\mathrm{Cu}$ cumber mosaic virus. Mol. Plant-Microbe Interact. 3:188-192.

Ryu, C.-M., Murphy, J. F., Mysore, K. S., and Kloepper, J. W. 2004. Plant growth-promoting rhizobacteria systemically protect Arabidopsis thaliana against Cucumber mosaic virus by a salicylic acid and NPR1independent and jasmonic acid-dependent signaling pathway. Plant $\mathrm{J}$. 39:381-392.

Sekine, K.-T., Nandi, A., Ishihara, T., Hase, S., Ikegami, M., Shah, J., and Takahashi, H. 2004. Enhanced resistance to Cucumber mosaic virus in the Arabidopsis thaliana ssi2 mutant is mediated via an SA-independent mechanism. Mol. Plant-Microbe Interact. 17:623-632.

Singh, D. P., Moore, C. A., Gilliland, A., and Carr, J. P. 2004. Activation of multiple anti-viral defence mechanisms by salicylic acid. Mol. Plant Pathol. 5:57-63.

Smith-Becker, J., Keen, N. T., and Becker, J. O. 2003. Acibenzolar-Smethyl induces resistance to Colletotrichum lagenarium and cucumber mosaic virus in cantaloupe. Crop Prot. 22:769-774.

Thaler, J. S., Owen, B., and Higgins, V. J. 2004. The role of the jasmonate response in plant susceptibility to diverse pathogens with a range of lifestyles. Plant Physiol. 135:530-538.

Truernit, E. 2001. The importance of sucrose transporters. Curr. Biol. 11:R169-R171.

van Bel, A. J. E. 2003. The phloem, a miracle of ingenuity. Plant Cell Environ. 26:125-149.

Wang, Y., Lee, K.-C., Gaba, V., Wong, S.-M., Palukaitis, P., and Gal-On, A. 2004. Breakage of resistance to Cucumber mosaic virus by coinfection with Zucchini yellow mosaic virus: enhancement of CMV accumulation independent of symptom expression. Arch. Virol. 149:379-396.

White R. F., Antoniw, J. F., Carr, J. P., and Woods, R. D. 1983. The effects of aspirin and polyacrylic acid on the multiplication and spread of TMV in different cultivars of tobacco with and without the N-gene. Phytopathol. Z. 107:224-232.

Wong, C. E., Carson, R. A. J., and Carr, J. P. 2002. Chemically induced virus resistance in Arabidopsis thaliana is independent of pathogenesisrelated protein expression and the NPR1 gene. Mol. Plant-Microbe Interact. 15:75-81.

Xie, Z. X., and Chen, Z. X. 1999. Salicylic acid induces rapid inhibition of mitochondrial electron transport and oxidative phosphorylation in tobacco cells. Plant Physiol. 120:217-225.

Xie, Z. X., Fan, B. F., Chen, C. H., and Chen, Z. X. 2001. An important role of an inducible RNA-dependent RNA polymerase in plant antiviral defense. Proc. Natl. Acad. Sci. U.S.A. 98:6516-6521.

Yang, S.-J., Carter, S. A., Cole, A. B., Cheng, N.-H., and Nelson, R. S. 2004. A natural variant of a host RNA-dependent RNA polymerase is associated with increased susceptibility to viruses by Nicotiana benthamiana. Proc. Natl. Acad. Sci. U.S.A. 101:6297-6302. 